\title{
IMPLEMENTASI METODE GRABBING PADA WEB PENYEDIA INFORMASI BEASISWA
}

\author{
Popon Dauni $^{1}$, Egi Ferdiana ${ }^{2}$, Cepy Slamet ${ }^{3}$, Aldy Rialdy Atmadja $^{4}$ \\ 1,2,3,4 Jurusan Teknik Informatika, Fakultas Sains dan Teknologi \\ UIN Sunan Gunung Djati Bandung \\ Jl. A.H. Nasution 105, Bandung 40614 Indonesia \\ 1popon.dauni@if.uinsgd.ac.id, ${ }^{2}$ egifergiana17@gmail.com, \\ ${ }^{3}$ cepy.slamet@uinsgd.ac.id, ${ }^{4}$ aldy@if.uinsgd.ac.id
}

\begin{abstract}
ABSTRAK
Beasiswa adalah pemberian berupa bantuan keuangan dalam pendidikan yang diberikan kepada pelajar yang bertujuan untuk keberlangsungan pendidikannya. Beasiswa tersebut diberikan oleh suatu lembaga pemerintah atau sebuah yayasan. Informasi mengenai beasiswa yang ditawarkan biasanya dapat kita lihat di internet melalui suatu website. Jenis beasiswa yang ditawarkan juga beraneka ragam, baik beasiswa dalam negeri ataupun beasiswa dari luar negeri. Namun, banyaknya penyedia beasiswa yang menggunakan website membuat pencari beasiswa kesulitan untuk mendapat informasi beasiswa dalam satu waktu. Penelitian ini bertujuan untuk membuat portal informasi yang dapat memudahkan para pencari beasiswa untuk mendapatkan informasi yang dibutuhkan. Metode grabbing digunakan dalam penelitian ini untuk mengambil informasi pada suatu halaman website yang dituju, kemudian dikumpulkan dalam satu portal website yang baru. Sehingga, apabila terdapat informasi baru terkait beasiswa dapat dengan mudah untuk didapatkan. Aplikasi ini menggunakan bahasa pemrograman PHP dan menggunakan library cURL dalam berkomunikasi dengan berbagai internet protokol.
\end{abstract}

Kata Kunci: Beasiswa, portal web, Grabbing, cURL

\begin{abstract}
The scholarship is a gift of financial assistance to students who aim for continuity of their education. The scholarship can be awarded by a government or foundation. The information of scholarship usually can be accessed on a website by using the internet. There are many types of scholarship such as for domestic and overseas scholarship. However, the amount of scholarship information makes the peoples difficult to find the scholarship exactly at a time. The purpose of research is making a portal information to facilitate scholarship seekers to obtain required information of scholarship. Grabbing method is able to retrieve information on a website and collected in a new website scholarship portal. Thus, if there is a new scholarship information, the portal can be easily obtained getting information. PHP programming language and cURL library are implemented in this research to communicate with various internet protocols.
\end{abstract}

Keywords: Scholarship, web portal, Grabbing method, cURL

DOI: $10.15408 /$ jti.v10i2.6823 


\section{PENDAHULUAN}

Beasiswa adalah pembiayaan yang tidak bersumber dari pendanaan sendiri atau orangtua, akan tetapi diberikan oleh pemerintah, perusahaan swasta, kedutaan, universitas, serta lembaga pendidik atau peneliti[1]. Beasiswa memiliki berbagai macam jenis diantaranya yaitu beasiswa penghargaan, bantuan dan atletik[2].

a. Beasiswa Penghargaan

Beasiswa ini biasanya diberikan kepada kandidat yang memiliki keunggulan akademik. Beasiswa ini diberikan berdasarkan prestasi akademik secara keseluruhan.

b. Beasiswa Bantuan

Jenis beasiswa bantuan dipergunakan untuk mendanai kegiatan akademik pelajar yang memiliki keterbatasan ekonomi, tetapi memiliki prestasi. Komite beasiswa biasanya memberikan beberapa penilaian terkait layaknya seseorang mendapat beasiswa ini.

c. Beasiswa Atletik

Beasiswa diperuntukkan kepada mereka yang memiliki prestasi, khususnya dalam bidang olahraga.

d. Beasiswa Penuh

Beasiswa penuh diberikan kepada seseorang secara penuh untuk menutupi kebutuhan akademik, seperti: kebutuhan hidup, buku, dan biaya pendidikan.

Informasi terkait beasiswa saat ini tersedia dengan memanfaatkan teknologi informasi berupa internet, dengan demikian informasi beasiswa akan dengan cepat sampaidiperoleh oleh banyak orang. Semakin banyak penyedia beasiswa yang memanfaatkan internet sebagai media penyebaran informasi, maka semakin banyak pula alamat-alamat website penyedia beasiswa. Namun, banyaknya website penyedia informasi beasiswa membuat pencari beasiswa kesulitan dalam memperoleh informasi beasiswa dalam satu waktu. Di samping itu, User sebagai pencari beasiswa tentunya harus membuka laman beasiswa tersebut satu persatu agar dapat memperoleh banyak informasi beasiswa. Dengan demikian diperlukan sebuah aplikasi yang mengumpulkan informasi terkait beasiswa. Istilah aplikasi berasal dari bahasa inggris application yang berarti penerapan, lamaran ataupun penggunaan. Secara umum pengertian aplikasi adalah software yang dibuat oleh suatu perusahaan komputer untuk mengerjakan tugastugas tertentu[3], aplikasi dapat berupa platform yang berbeda-beda. Namun pada penelitian ini pengembangan yang dilakukan yakni membuat portal web untuk informasi beasiswa.

Metode Grabbing merupakan suatu teknik untuk mengambil teks atau secara umum objek, yang terdapat pada halaman website yang kemudian akan diletakkan ke dalam satu website[4]. Data yang diambil dalam metode grabbing bisa berupa text, gambar, file, basis data maupun kesuluruhan halaman dalam suatu website HTML tersebut. Teknik ini memanfaatkan CURL pada PHP untuk mendapatkan informasinya. Libcurl / CURL, yaitu sebuah library pada PHP yang diciptakan oleh Daniel Stenberg, yang memungkinkan Anda untuk terhubung dan berkomunikasi dengan berbagai jenis server dengan berbagai jenis protocol[5].

Metode grabbing dapat diterapkan ke dalam sistem informasi beasiswa. Dengan metode grabbing, informasi beasiswa ada dalam berbagai website penyedia beasiswa, dapat diambil dan diterapkan kedalam satu website. Dengan begitu, user hanya perlu membuka satu alamat website untuk dapat memperoleh banyak nformasi beasiswa. Untuk itu, dibuatlah "Implementasi Metode Grabbing Pada Web Penyedia Informasi Beasiswa".

\section{TINJAUAN PUSTAKA}

\subsection{Metode Grabbing}

Metode Grabbing merupakan suatu teknik untuk mengintegrasikan semua informasi yang terdapat di website untuk mengambil data dari tempat atau dari sumber lain[6]. Dalam PHP script, metode grabbing diimplementsikan dengan menggunakan perintah StrPos (string character). Hasil dari fungsi ini menyatakan sebuah karakter dalam string. Bila argument ketiga StrPos tidak diberikan, maka nilainya dianggap sama dengan 0 (pencarian dimulai dari awal string).

Dengan metode grabbing, informasi yang ada dalam beberapa halaman website, dapat diakses melalui satu halaman website saja sehingga akan memberikan kemudahan bagi user untuk memperoleh informasi dengan cepat dan akurat. Beberapa kasus yang menerapkan metode grabbing di dalamnya diantaranya website penerbangan, website bank, website kereta api dan lain-lain. Di bawah ini, contoh 
script metode grabbing yang diterapkan untuk mengambil informasi cuaca terkini:

$<$ ?php

function grabbing(\$url) \{ \$data

= curl_init();

curl_setopt(\$data,

CURLOPT_RETURNTRANS

FER, 1); curl_setopt(\$data,

CURLOPT_URL, \$url);

\$output = curl_exec(\$data); curl_close(\$data) \} return \$output;

\$ambilhtml =

grabbing('http://bmkg.go.id/cuaca/cuaca-

aktual-bandara.bmkg'); \$filter $=$ explode('div class="container content"', \$ambilhtml);

\$filterakhir $=$ explode('</div $>$ ', \$filter[1]); echo \$filterakhir[0];

// source:

http://h4nk.blogspot.com/2013/05/teknik?> grabbing-dengan-curl-php.html

Dari script tersebut, maka akan menampilkan informasi mengenai perkiraan cuaca pada hari dan tanggal saat dilakukan akses website tersebut. Informasi perkiraan cuaca, bersumber dari website resmi Badan Meteorologi Klimatologi dan Geofisika (BMKG) di situs www.bmkg.go.id.

\section{Informasi Cuaca Aktual Bandara}

\begin{tabular}{|c|c|c|c|c|c|c|c|c|}
\hline Batdara Sorinn & 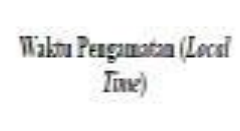 & $\begin{array}{l}\text { Anh } \\
\text { (bai) }\end{array}$ & $\begin{array}{l}\text { Angin } \\
\text { Kecęatan } \\
\text { (knjan) }\end{array}$ & $\begin{array}{l}\text { Jarak Papdang } \\
\text { (kn) }\end{array}$ & Canca & $\begin{array}{l}\text { Subn } \\
(\mathrm{C})\end{array}$ & $\begin{array}{l}\text { Trik Enbun } \\
\text { (C) }\end{array}$ & $\begin{array}{l}\text { Tekunan Tdara } \\
\qquad\left(\mathbb{P} P_{2}\right)\end{array}$ \\
\hline 1 Sutnilkniar Wuda - Burca doth & $2017-0 .-16$ 153000 $\mathrm{WB}$ & $\begin{array}{l}\text { Barat } \\
\text { Deyaz }\end{array}$ & 3.7. & $=10$ & Beraman & 31. & 22 & 1005 \\
\hline 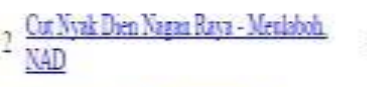 & 3017-0.-16 13W:00 NBB & Barst & 111 & $=10$ & Cenh-berman & 32 & 28 & 1008 \\
\hline 3 Maithssith-Lbkserume & $2017-60-16$ 13:W:00 $~ W B B$ & Seltrm & 7.4 & $=10$ & Cexh-berman & 33 & 13 & 1006 \\
\hline 4 Brab-Grang Sorl & $2017-(6-1615 W 0007 \mathrm{NB}$ & Ctana & 93 & $=10$ & Berman & 31 & 28 & 1006 \\
\hline 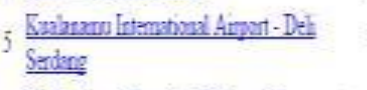 & $3017-05-16153000) \times B$ & Irenr & 130 & $y=10$ & Berman & 32 & 36 & 1004 \\
\hline $6 \frac{\text { Dr Fedmond Lumben Istrat - Prangson }}{\text { Shoolge) }}$ & $3017-05-16153000) \times B$ & Brarlart & & $y=10$ & Beranan & 31 & It & 1005 \\
\hline 7 dak Godeng - Padang Sdecroun & $2017-05-1615 \%=0)$ NB & $\begin{array}{l}\text { Barst } \\
\text { Deya }\end{array}$ & 130 & $y=10$ & Berma & 33 & 21 & 1005 \\
\hline 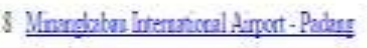 & $3017-05-161536007 \mathrm{NB}$ & Barst & IA & $z=10$ & Cesh-berman & 32 & it & 1005 \\
\hline 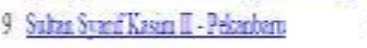 & $2017-05-16153000 \% \mathrm{NB}$ & Terggen & 111 & $=10$ & Berman & 33 & 26 & 1004 \\
\hline 10 DeartiPato-Earni & $2017-60-1615 \mathrm{WW} \times \mathrm{NB}$ & Terggen & 7.4 & 70 & Berman & 23 & 20 & 1010 \\
\hline
\end{tabular}

Gambar 1. Tampilan informasi perkiraan cuaca dari Badan Meteorologi Krimatologi dan Geofisika

(BMKG)

Untuk dapat berkomunikasi dengan internet protokol, metode grabbing menggunakan sebuah tools command-line yaitu curl[4]. Curl memungkinkan pengguna (user) dapat terhubung berkomunikasi dengan berbagai jenis server dengan berbagai jenis protokol. Libcurl, saat ini dapat terhubung dengan jenis protokol http, https, ftp, gopher, telnet, dict, file dan idap. Selain itu, libcurl juga mendukung sertifikat HTTPS, HTTP, POST, PUT, FTP upload, proxy, cookies, serta otentikasi pengguna dan password dalam bentuk HTTP[7].

Untuk dapat mengaktifkan libcurl, dapat dilakukan dengan menghilangkan tanda “;” pada extension=php_curl yang terdapat dalam file xampp/php.ini. Dalam PHP, sebuah sesi curl diawali dengan sebauh fungsi curl_init() dan diakhiri dengan fungsi curl_close(). Eksekusi curl terjadi saat pemanggilan fungsi curl_exec(). Terdapat beberapa pengaturan dalam curl diantaranya pengaturan cookie, request HTTP GET/POST, user agent, HTTP referrer, dilakukan dengan fungsi curl_setopt().

\section{METODOLOGI}

Dalam pengembangan website ini, metode yang digunakan adalah Rational Unified Process (RUP). Terdapat 2 dimensi dalam penerapan metode RUP. 2 dimensi tersebut adalah dimensi vertikal dan dimensi horizontal. Pada dimensi vertikal, fase. Berikut 
ini akan dijelaskan fase-fase yang diterapkan dalam penggunaan metode RUP:

1. Inception

Pada tahap ini, dilakukan pemodelan proses bisnis yang dibutuhkan dan mendefinisikan kebutuhan user yang akan dibuat. Aktivitas yang digunakan dalam fase ini adalah Bussines Modelling dan Requirement Workflow.

2. Elaboration

Tahap ini lebih difokuskan pada perencanaan asrsitektur sistem, dan mendeteksi apakan arsitektur yang dbuat diinginkan, serta mendeteksi kemungkinan resiko yang akan terjadi dari arsitektur yang dibuat. Tahap ini lebih pada analisis dan sedain sistem serta implementasi sistem yang fokus pada sistem. Aktivitas yang digunakan dalam fase ini adalah Analysis and Design.

3. Construction

Pada tahap ini dilakukan pengembangan komponen dan fitur-fitur sistem. Pada tahap ini, lebih pada implementasi dan pengujian sistem yang fokus pada implementasi perangkat lunak pada kode program. Aktivitas yang digunakan dalam fase ini adalah Implementation dan Test.

Sementara itu, fase Transition tidak diterapkan dalam pengembangan website ini karena pada fase ini, website harus benar-benar dibuat dan diuji agar dapat diakses dan digunakan oleh banyak orang. Sedangkan saat ini, website dibuat untuk kebutuhan pribadi.

Untuk membuat website penyedia informasi beasiswa, diperlukan kemampuan menggunakan bahasa pemograman PHP sebagai basic dalam pembuatan aplikasi berbasis web ini. Berikut digambarkan kinerja metode grabbing dalam mengambil halaman website:

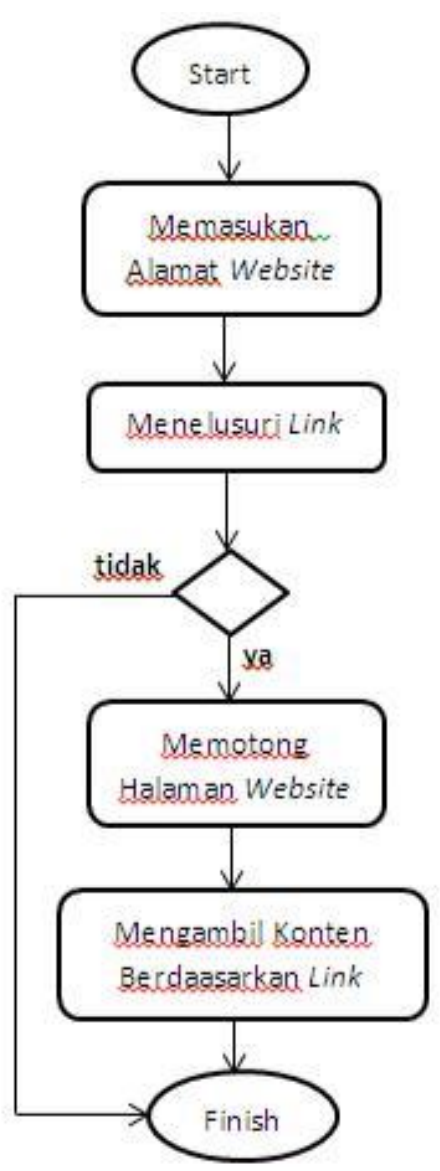

Gambar 1. Flowchart Metode Grabbing Dalam Mengambil Halaman Website

\subsection{Arsitektur Sistem}

Untuk memenuhi kebutuhan website penyedia informasi beasiswa yang dapat mengambil informasi beasiswa dari berbagai sumber website penyedia beasiswa maka diberikan sebuah design arsitektur sistem sebagai berikut: 


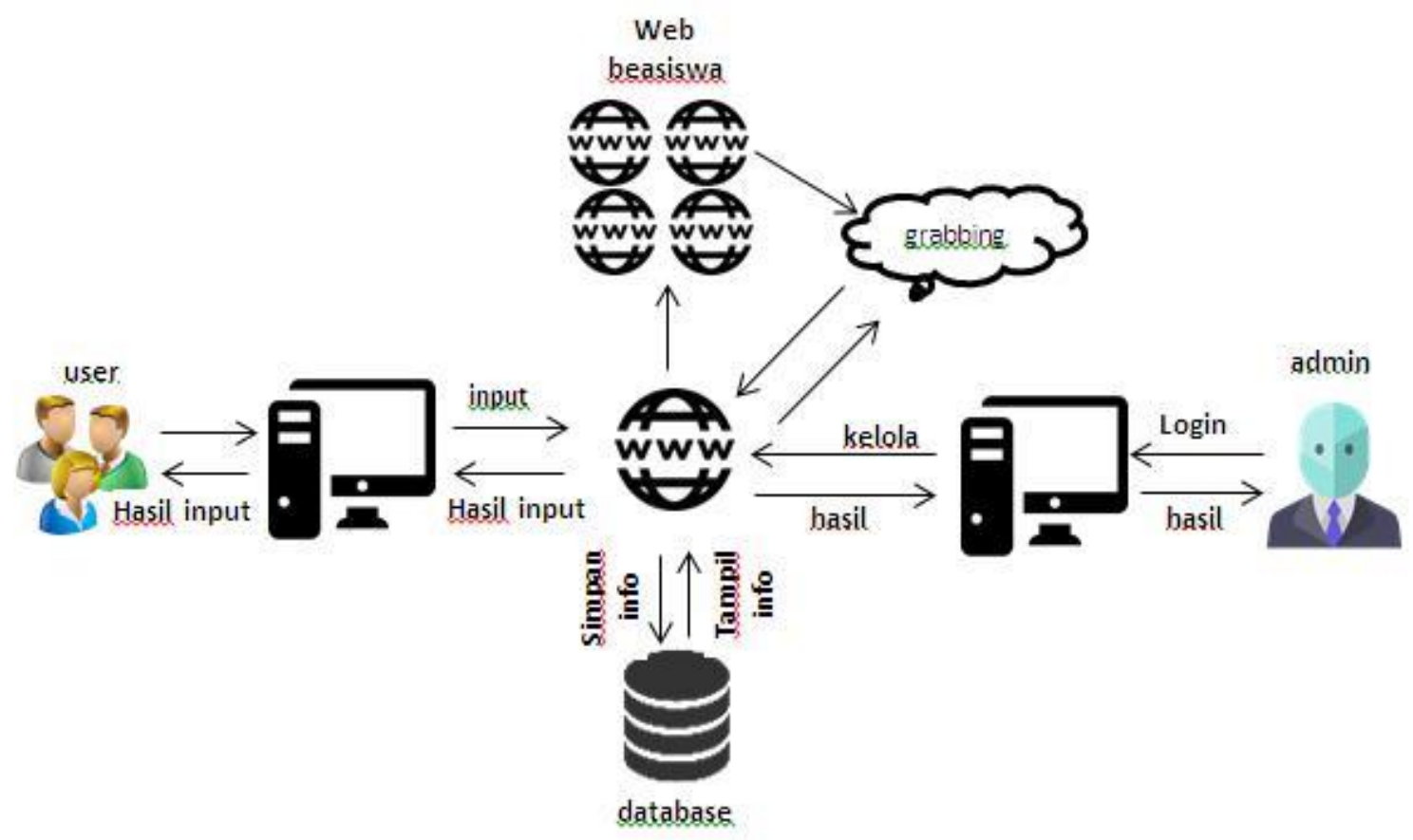

Gambar 2. Arsitektur sistem

Pada Gambar 2 dapat dilihat terdapat icon dan admin sebagai objek yang saling berkomunikasi. User dalam hal ini sebagai pencari beasiswa, akan mengakses website yang telah meyimpan informasi beasiswa. Setelah website berhasil diakses, maka informasi beasiswa akan muncul sehingga user tinggal memilih beasiswa yang dibutuhkan. Sedangkan admin, bekerja sebagai pengelola website yang menyediakan informasi beasiswa. Admin dapat mengelola informasi beasiswa yang masuk seperti menghapus, edit, ataupun menambah informasi beasiswa jika ada website penyedia informasi beasiswa baru. Setelah berhasil ditambahkan, informasi yang berhasil diambil akan tersimpan secara otomatis di dalam database yang telah disediakan sehingga saat user mengakses website, informasi beasiswa akan muncul sesuai dengan yang ada dalam database.

\subsection{Use Case Diagram}

Use Case Diagram dapat menjelaskan aktivitas yang dilakukan oleh aktor dan sistem. Berikut adalah: 


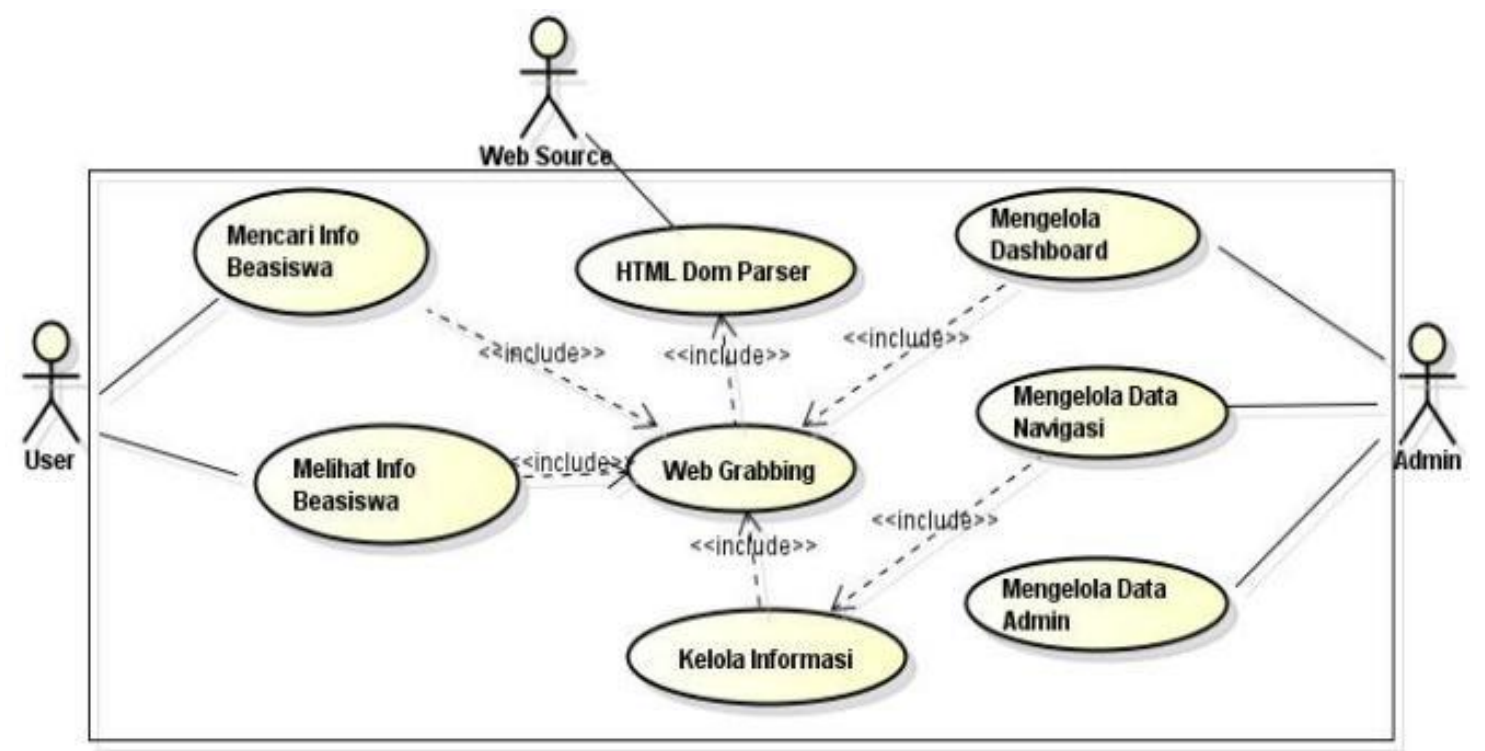

Gambar 3. Use case diagram

Pada Gambar 3, dijelaskan terdapat 3 aktor yakni user, admin dan web source. Dalam hal ini, user sebagai pencari beasiswa, admin sebagai pengelola website dan web source sebagai sumber website yang menyediakan informasi beasiswa. Aktor user memiliki 2 aktivitas yakni mencari informasi serta melihat informasi beasiswa. Sementara admin memiliki 3 aktivitas yakni mengelola dashboard, mengelola data navigasi serta mengelola admin.

Sedangkan web source merupakan sumber website penyedia beasiswa yang akan diambil informasinya.

\section{HASIL DAN PEMBAHASAN}

Pengujian hasil penelitian ini adalah dengan menggunakan pengujian blackbox. Pengujian blackbox dilakukan untuk menguji apakah sistem dibuat sesuai dengan kebutuhan. Pengujian black-box dilakukan setelah proses pembuatan aplikasi selesai dan sebelum didistribusikan. Di bawah ini adalah hasil pengujian dengan metode blackbox atau pengujian fungsionalitas sistem yang dilakukan.
Tabel 1. Pengujian sistem

\begin{tabular}{|c|c|c|c|c|}
\hline \multirow[t]{2}{*}{$\mathrm{Kd}$} & \multirow[t]{2}{*}{ Skenario } & \multicolumn{2}{|c|}{ Hasil } & \multirow{3}{*}{$\begin{array}{c}\text { Ket } \\
\text { Berhasil }\end{array}$} \\
\hline & & Sukses & Gagal & \\
\hline F01 & $\begin{array}{l}\text { Mencari } \\
\text { informasi }\end{array}$ & $\sqrt{ }$ & & \\
\hline F02 & $\begin{array}{l}\text { Melihat } \\
\text { informasi }\end{array}$ & $\sqrt{ }$ & & Berhasil \\
\hline F03 & $\begin{array}{l}\text { Menampilkan } \\
\text { laporan hasil } \\
\text { grabbing }\end{array}$ & $\sqrt{ }$ & & Berhasil \\
\hline F04 & $\begin{array}{l}\text { Melakukan } \\
\text { Proses Teknik } \\
\text { Grabbing }\end{array}$ & $\sqrt{ }$ & & Berhasil \\
\hline F05 & $\begin{array}{l}\text { Menyimpan } \\
\text { hasil Proses } \\
\text { Grabbing }\end{array}$ & $\sqrt{ }$ & & Berhasil \\
\hline F06 & $\begin{array}{l}\text { Mengelola } \\
\text { Data Grabbing }\end{array}$ & $\sqrt{ }$ & & Berhasil \\
\hline F07 & $\begin{array}{l}\text { Mengelola } \\
\text { Perawatan }\end{array}$ & $\sqrt{ }$ & & Berhasil \\
\hline F08 & $\begin{array}{l}\text { Mengelola } \\
\text { Data Admin }\end{array}$ & $\sqrt{ }$ & & Berhasil \\
\hline
\end{tabular}

Selain itu, dilakukan pula pengujian pada metode grabbing untuk dapat mengetahui seberapa cepat metode grabbing mengambil informasi dari satu halaman website. Pengujian dilakukan dengan mengambil informasi dari 4 website penyedia beasiswa yakni beasiswapascasarjana.com, scholarshipportal.com, scholar4dev.com, dan indbeasiswa.com. 
Tabel 2. Pengujian pada website scholar4dev.com

\begin{tabular}{|c|c|c|c|c|c|}
\hline \multicolumn{6}{|c|}{ Hasil Pengujian } \\
\hline Waktu Pengujian & $1 \mathrm{x}$ & $2 \mathrm{x}$ & $3 x$ & $4 \mathrm{x}$ & $5 x$ \\
\hline Lama Pengujian & $12 \mathrm{~m}$ & $12 \mathrm{~m}$ & $10 \mathrm{~m}$ & $13 \mathrm{~m}$ & $10 \mathrm{~m}$ \\
\hline Jumlah Informasi & 17 & 15 & 15 & 18 & 15 \\
\hline
\end{tabular}

Tabel 3. Pengujian pada website beasiswapascasarjana.com

\begin{tabular}{|c|c|c|c|c|c|}
\hline \multicolumn{6}{|c|}{ Hasil Pengujian } \\
\hline Waktu Pengujian & $1 \mathrm{x}$ & $2 \mathrm{x}$ & $3 \mathrm{x}$ & $4 \mathrm{x}$ & $5 x$ \\
\hline Lama Pengujian & $12 \mathrm{~m}$ & $10 \mathrm{~m}$ & $10 \mathrm{~m}$ & $13 \mathrm{~m}$ & $10 \mathrm{~m}$ \\
\hline Jumlah Informasi & 15 & 15 & 20 & 18 & 18 \\
\hline
\end{tabular}

Tabel 4. Pengujian pada website scholarshipportal.com

\begin{tabular}{|c|c|c|c|c|c|}
\hline \multicolumn{6}{|c|}{ Hasil Pengujian } \\
\hline Waktu Pengujian & $1 \mathrm{x}$ & $2 \mathrm{x}$ & $3 \mathrm{x}$ & $4 \mathrm{x}$ & $5 x$ \\
\hline Lama Pengujian & $10 \mathrm{~m}$ & $10 \mathrm{~m}$ & $10 \mathrm{~m}$ & $10 \mathrm{~m}$ & $12 \mathrm{~m}$ \\
\hline Jumlah Informasi & 16 & 17 & 16 & 15 & 18 \\
\hline
\end{tabular}

Tabel 5. Pengujian pada website indbeasiswa.com

\begin{tabular}{cccccc}
\hline \multicolumn{5}{c}{ Hasil Pengujian } & \\
\hline Waktu Pengujian & $1 \mathrm{x}$ & $2 \mathrm{x}$ & $3 \mathrm{x}$ & $4 \mathrm{x}$ & $5 \mathrm{x}$ \\
Lama Pengujian & $10 \mathrm{~m}$ & $15 \mathrm{~m}$ & $13 \mathrm{~m}$ & $12 \mathrm{~m}$ & $10 \mathrm{~m}$ \\
Jumlah Informasi & 18 & 15 & 15 & 17 & 20 \\
\hline
\end{tabular}

Berdasarkan hasil penelitian yang dilakukan, dapat disimpulkan bahwa rata-rata waktu yang dibutuhkan untuk mengambil halaman informasi dari satu website membutuhkan waktu 10 hingga 15 menit dengan informasi yang didapat 15 hingga 20 informasi dalam satu website.

\section{PENUTUP}

\subsection{Kesimpulan}

Setelah melalui tahapan-tahapan yang sesuai dengan metode metode pengembangan perangkat lunak Rational Unified Process (RUP) dalam pembangunan aplikasi ini dapat disimpulkan bahwa metode Grabbing berhasil diterapkan dalam mengambil informasi beasiswa dari berbagai website penyedia beasiswa.

Metode Grabbing efektif digunakan dalam website penyedia beasiswa dimana informasi yang terdapat dalam website lain dapat diambil baik sebagian maupun keseluruhan isi yang kemudian dapat diterapkan ke dalam satu website. Metode grabbing cocok digunakan untuk mengambil informasi dari halaman web yang sumber informasinya tidak banyak. Karena metode grabbing memakan waktu yang lama untuk mengambil informasi.

\subsection{Saran}

Untuk ke depannya sistem pencarian dikembangkan dengan menerapkan algoritma pencarian seperti string matching sehingga informasi bisa didapatkan dengan baik. Mampu melakukan pencarian informasi secara otomatis tanpa harus menginput URL, yakni dengan penerapan text mining dimana website dapat mencari informasi secara otomatis berdasarkan kata kunci yang diinputkan. Dapat terintegrasi dengan email user jika terdapat informasi beasiswa terbaru.

\section{DAFTAR PUSTAKA}

[1] A. Gafur, S. Yulianti, and N. Hidayat, Cara Mudah Mendapatkan Beasiswa. Jakarta: Penebar Plus, 2008.

[2] I. Lekmi, "Analisis Implementasi Program Beasiswa Miskin Bagi Siswa Sekolah pada Dinas Pendidikan Kabupaten Kampar," Universitas Negeri Sultan Syarif Kasim Riau, 2014.

[3] R. M. Puspita, Arini, and S. U. Masrurah, "Pengembangan Aplikasi Penjadwalan Kegiatan Pelatihan Teknologi Informasi Dan Komunikasi Dengan Algoritma Genetika," J. Online Inform., vol. 1, no. 2, pp. 76-81, 2016.

[4] Sumarsono and A. S. Husin, "Sistem Terintegrasi Portal Web Perguruan Tinggi Agama Islam Negeri Menggunakan Metode Grabbing," Kaunia, vol. IX, no. 2, pp. 21-26, 2013.

[5] H. Purwoko, "Pemanfaatan CURL Pada PHP Guna Mendapatkan Informasi 
Malware Dengan Memanfaatkan AVG Thread Labs," Fakt. Exacta, vol. 9, no. 1, pp. 102-108, 2016.

[6] Benny, "Sistem Informasi Aktual Berbasis WAP Dengan Grabbing Method," 2011.

[7] Jonathan Narendra, Suprihadi, and Y. R. Beeh, "Layanan Service Aplikasi SMS Captcha Pada Web Berbasis CURL Dengan Menggunakan JSON Format," $J$. Teknol. Informasi-Aiti, vol. 8, no. 1, pp. 42-60, 2011. 